\title{
Flow behaviour and local concentration of coarse particles-water mixture in inclined pipes
}

\author{
Pavel Vlasak*, Zdenek Chara, Jiri Konfrst \\ Institute of Hydrodynamics of Czech Academy of Sciences, v. v. i., Pod Patankou 30/5, 160 00, Prague 6, Czech Republic. \\ E-mails: vlasak@ih.cas.cz; chara@ih.cas.cz; konfrst@ih.cas.cz \\ *Corresponding author. Tel.: +420 233109019. Fax:+420 233324861. E-mail: vlasak@ih.cas.cz
}

\begin{abstract}
Narrow particle size distribution basalt pebbles of mean particle size $11.5 \mathrm{~mm}$ conveyed by water in the pipe sections of different inclination were investigated on an experimental pipe loop, consisting of smooth stainless steel pipes of inner diameter $D=100 \mathrm{~mm}$. Mixture flow-behaviour and particles motion along the pipe invert were studied in a pipe viewing section, the concentration distribution in pipe cross-section was studied with the application of a gamma-ray densitometer. The study refers to the effect of mixture velocity, overall concentration, and angle of pipe inclination on chord-averaged concentration profiles and local concentration maps, and flow behaviour of the coarse particle-water mixtures. The study revealed that the coarse particle-water mixtures in the inclined pipe sections were significantly stratified, the solid particles moved principally close to the pipe invert, and for higher and moderate flow velocities particle saltation becomes the dominant mode of particle conveying.
\end{abstract}

Keywords: Coarse particle mixture; Concentration distribution; Effect of pipe inclination; Gamma-ray radiometry; Hydraulic conveying; Mixture flow behaviour.

\section{INTRODUCTION}

Hydraulic transport is commonly used for transport of bulk materials, like coal, ores, and different waste materials, mostly relatively fine particles, which in the turbulent flow are supported by turbulent diffusion in the core of the flow. Near the pipe wall a lift force, associated with slip velocity and concentration profile contributed to particle lift-off. When the particle size is larger than the viscous sub-layer thickness, Saffman force supports particle movement in pipe (Wilson et al., 2010). According to Campbell et al. (2004) Saffman force, induced due to the shear of the fluid itself, together with Magnus force (due to the particle rotation) could reach a significant fraction of the total weight of particles (about 40\%).

Pipeline transport of coarse particles in the form of heterogeneous mixtures is of special interest in, e.g. dredging, building, mining (e. g. the Alberta sands petroleum extraction), or poly-metallic nodules transport from the ocean bottom to the surface (Vlasak and Chara, 2007; Vlasak et al., 2011, 2012). The flow of heterogeneous solid-liquid mixtures in a horizontal pipe may be defined as the flow with an asymmetrical concentration and velocity distribution. A layered flow pattern with a bed layer and a skewed concentration and velocity distribution generally exist for these slurries (Wilson et al., 2006). The first mechanistic approach for coarse particle-water mixture flow was probably that of Newitt et al. (1955).

They distinguished between fluid friction, and particle-wall frictions of the Coulomb type, and defined coarse particle conveyance as flow with a sliding bed and a skipping motion (saltation) of conveyed particles.

A slurry flow mechanism can be theoretically described by a set of differential equations for the conservation of mass, momentum and energy, the so called microscopic model (Shook and Roco, 1991). Unfortunately, the microscopic models employed a very large number of empirical coefficients, and no experimental technique is able to provide enough information on the slurry flow mechanism at a microscopic level, and the model remains only theoretical.
A compromise between the microscopic and empirical approaches is macroscopic modelling, where the conservation equations are formulated using averaged quantities over the control volume. Wilson (1976) proposed a two-layer model for settling slurries with fully stratified flow pattern, where all particles are supposed to be concentrated in the lower portion of the pipe with concentration approaching the loose-packed value, and the Coulombic contribution to particle-wall friction is dominant. In the upper layer only clear fluid is assumed. Based on experimental data from the large test pipelines of the Saskatchewan Research Council the so called SRC two-layer model was introduced (Gillies et al., 1991; Shook and Roco, 1991; Shook et al., 1986). The two-layer model is based upon force balance for the upper and lower horizontal layers. When the relevant variables, including the Reynolds number, friction factor and Coulomb type friction are defined for each layer as well as the interfacial friction factor, the flow parameters could be determined (Gillies et al., 1991; Wilson, 1976).

A lot of theoretical or experimental studies have been carried out on transport of sand or fine particles in horizontal pipes (Durand, 1953; Newitt et al., 1955; Shook and Roco, 1991; Vlasak and Chara, 2007, 2011; Wilson et al., 1979). However, a relatively little research has been done on hydraulic conveying of gravel or bigger particles, especially in vertical and inclined pipes. A progress in the theoretical description of heterogeneous slurry flow is limited due to the lack of experimental data describing the flow behaviour and an inner structure of such slurry flow since study of the inner structure of settling mixtures flow is relatively difficult (Kao and Hwang, 1979; Sumner et al., 1990). A description of the slurry flow behavior and the inner structure are much more complex than measurements of only overall flow parameters (e.g. the flow rate, pressure drops, and overall concentration). The study of the inner structure of such flow is very difficult, since many well-known techniques suitable to determine the inner structure of fluid flow, e.g. Particle image velocimetry (PIV), Ultrasonic Doppler Velocity Profiler (UVP), and Laser Doppler velocimetry (LDV) can be 
used in solid-liquid mixtures with strong limitations (Vlasak et al., 2016).

Because the layers differ in the local solids concentration and velocity, there is a difference in the mean velocities of the particles and the liquid. Slip between the particles and the liquid results in a continuous transfer of energy from the fluid to the particle and from the particle to the pipe wall. The two-layer model may be used for the description of the fully or partially stratified flow even for finer particles (Gillies et al., 1991; Maciejewski et al., 1993; Shook et al., 1986) and also in the case of the non-Newtonian carrier (Pullum et al., 2004; Thomas and Wilson, 1987).

The present paper describes the experimental investigation of coarse-grained particle-water mixtures. It is focused on description of the effect of pipe inclination, mixture overall concentration and average velocity on local concentration distribution and slurry flow behaviour and brings new experimental results.

\section{EXPERIMENTAL EQUIPMENT AND MATERIAL}

The experimental investigation was carried out on the pipe loop of inner diameter $D=100 \mathrm{~mm}$, see Fig. 1. The loop consists of horizontal (A) and inclinable (B) pipe sections made from smooth stainless steel pipes and connected by abrasion resistant flexible hoses (12). Slurry was pumped from a mixing tank (1) by a centrifugal slurry pump GIW LCC-M 80-300 (2) with variable speed drive Siemens 1LG4283-2AB60-Z A11 (3). The pressure drops were measured by the differential pressure transducers Rosemount 1151DP (8) over 2-meter long measuring sections located in the horizontal and the inclined pipe sections. Glass viewing sections (7) situated on the end of the pipe sections were used to study the slurry flow behaviour. The mixture flow was recorded using a high speed digital camera NanoSence MK III + with a frequency up to 2000 frames per second, image resolution $1280 \times 1024$ pixels and frame rate $200 \mathrm{~Hz}$.

Slurry velocity was measured by a Krohne OPTIFLUX 5000 magnetic flow meter (9), mounted in the short vertical section (C) at the end of the loop. The flow divider (11) and the calibrated sampling tank (5) allow collection of slurry samples and measuring of the flow rate and delivered concentration. For easier operation the loop is also equipped by slide valves (4) and slurry output tank (6).

To measure vertical profiles of chord-averaged local in-situ volumetric concentration $c_{v}$ and $2 \mathrm{D}$-concentration maps, the

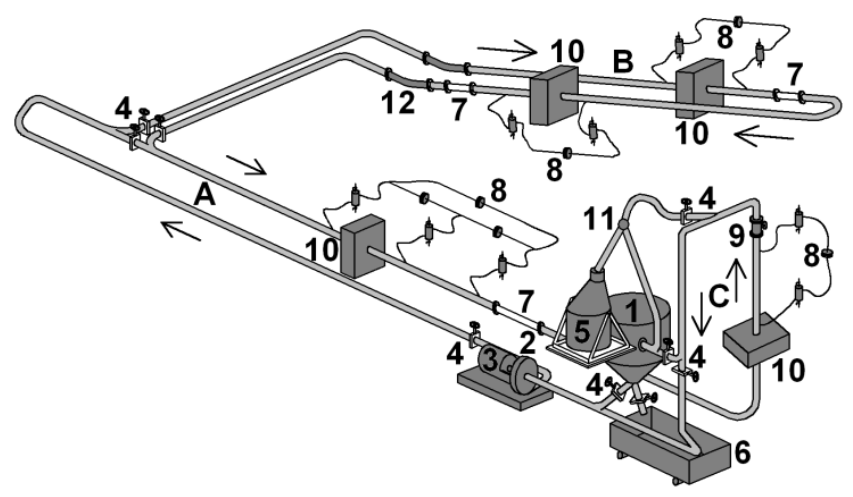

Fig. 1. Experimental test loop $D=100 \mathrm{~mm}$ (Institute of Hydrodynamics CAS, v. v. i.). loop is equipped with gamma-ray density meters (10) placed on a special support controlled by the computer, which serves for positioning of both the source and the detector to measure vertical concentration profiles (Vlasak et al., 2014c). The density meters (10) are mounted upstream of the measuring sections (8) in the horizontal (A) and inclinable (B) pipe sections.

The studied mixtures consist of graded basalt pebbles with a narrow particle size distribution (particle diameter, $d$, ranging from 8 to $16 \mathrm{~mm}$, particle density $\rho_{p}=2895 \mathrm{~kg} \mathrm{~m}^{-3}$ ). To avoid the effect of degradation (Wilson and Addie, 1997), degraded basalt pebbles were used, see Fig. 2. The particle size distribution was checked after individual measurements. Due to degradation the basalt pebbles with original value of mean diameter $d_{50}=12 \mathrm{~mm}$ changed slightly, the mean diameter was about $d_{50}$ $\approx 11.5 \mathrm{~mm}$, see Fig. 3, where the effect of pumping on particle size distribution is illustrated.

Water was used as the carrier liquid and the overall concentration, $c_{v}$, ranged from 3 to $15 \%$ (Vlasak et al., 2013a). To determine chord-averaged concentration profiles and concentration maps, three values of the mean slurry velocity, $V_{s}$, was used (in range from about $2.0 \mathrm{~m} \mathrm{~s}^{-1}$ to maximum values about $4.0 \mathrm{~m} \mathrm{~s}^{-1}$ ). Visualization of particle movement in bed layer was conducted for velocities close to deposition limit velocity $\left(V_{c r} \approx\right.$ $0.90 \mathrm{~m} \mathrm{~s}^{-1}$ ).



Fig. 2. The measured graded basalt pebbles $\left(d_{50}=11.5 \mathrm{~mm}\right)$.

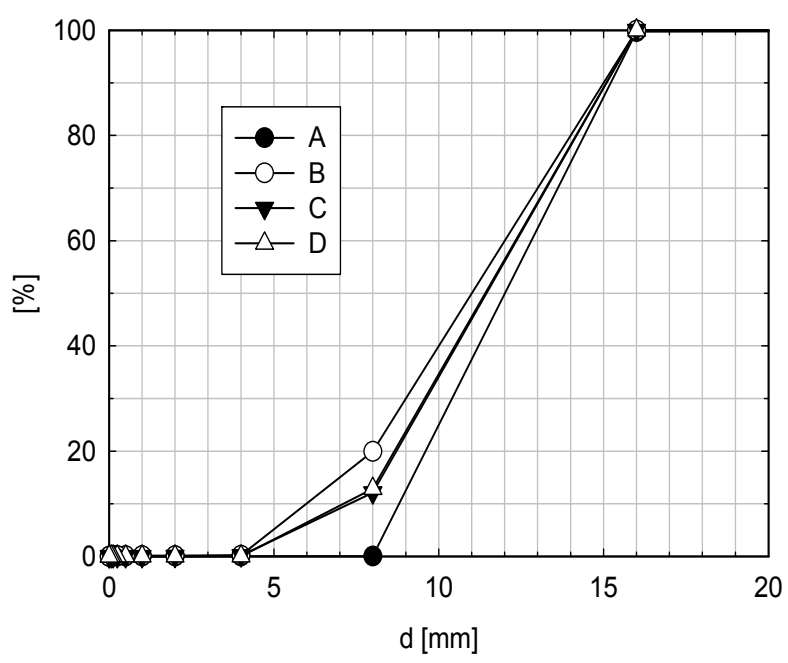

Fig. 3. Particle size distribution of graded basalt pebbles, effect of pumping $\left(\mathrm{A}-\right.$ original sample; $\mathrm{B}-c_{d}=3 \%, \mathrm{C}-c_{d}=6 \%, \mathrm{D}-c_{d}=$ $9 \%$, all after measurement). 


\section{MIXTURE FLOW BEHAVIOUR}

From visualization and high speed camera records we found, that particles slid and rolled along the pipe invert for flow velocities at about the deposition limit (e.g. $V_{s} \approx 0.90 \mathrm{~m} \mathrm{~s}^{-1}$ ). With increasing mixture velocity individual particles passed to the saltation mode and bottom formations similar to dunes originated (Newitt et al., 1955). This flow pattern resulted in pressure drop fluctuations (Vlasak et al., 2014b, 2015). For velocity interval between 1.5 to $2.5 \mathrm{~m} \mathrm{~s}^{-1}$ thicknesses of the bed formations decreased, dunes disaggregated, and a continuous sliding bed layer was observed.

For low mixture velocity values (e.g. $V_{s} \approx 1.1 \mathrm{~m} \mathrm{~s}^{-1}$ ) a stationary bed was observed, close to pipe invert particles were motionless; see e.g. particle No. 1 in Fig. 4 (upper panels). In the upper layer of the stationary bed particle No. 2 (and others in its vicinity) was slowly moving.

On the contrary particles above the "compact" bed moved relatively quickly in saltation mode. With increasing velocity (e.g. $V_{s} \approx 1.5 \mathrm{~m} \mathrm{~s}^{-1}$ ) particle No. 2 and similarly particles close to it increase their velocity, and even particles in the "compact" bed started slowly to move, see e.g. particle No. 1 in Fig. 4 (lower panels). For moderate and higher mixture velocities more and more particles lifted off the pipe bottom and moved in saltation mode.

The particle saltation became the dominant mode for particle movement, the particles moved in saltation mode with only temporal contact with pipe bottom and walls and with intensive rotation (Lukerchenko et al., 2006, 2009; Vlasak et al., 2014c). Velocities of the saltating particles were significantly higher than that of the sliding or rolling particles, moving in contact with the pipe wall. The particle velocities increased with increasing distance from the pipe invert (Vlasak et al., 2014a). The relatively high value of slip velocity between conveyed particles and carrier liquid, mutual particle-particle and particle-pipe interactions and collisions resulted in significant increase of the total pressure drop (Vlasak et al., 2011, 2012, 2014a).

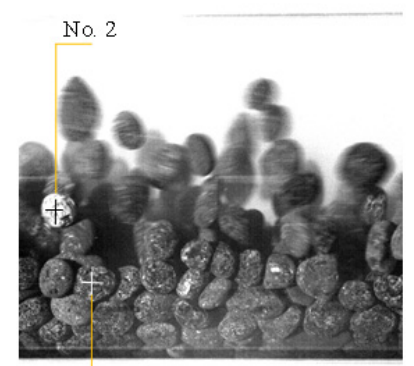

No. 1

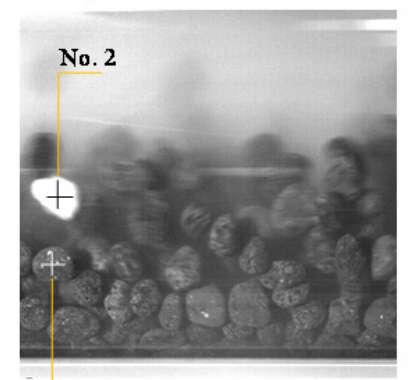

No. 1

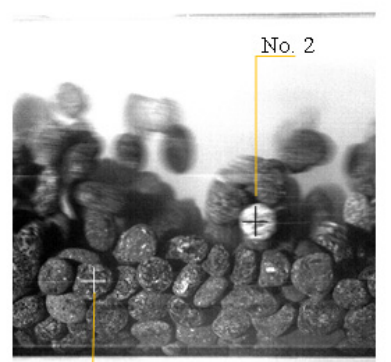

No. 1

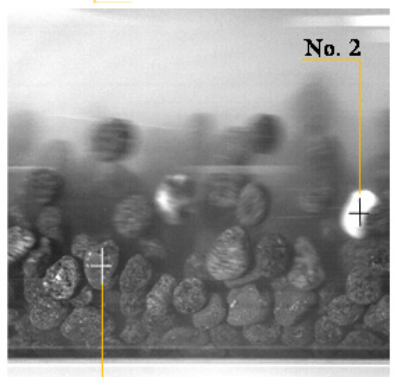

No. 1
Fig. 4. Particle movement in bed layer (mean mixture velocity $V_{s}=1.04$ and $1.35 \mathrm{~m} \mathrm{~s}^{-1}$, respectively).
These results confirm observation of Doron and Barnea that at low heterogeneous mixture velocities the particles in the upper portion of the bed layer may move, while the particles at layer close the pipe wall were motionless; these particles are not dragged along the pipe invert. Based on it, they proposed a three-layer model, where deposit layer consists of two components, the stable bed at the bottom with movable layer on the top, in which the particle velocity is higher than minimal value required for the particle motion. Above the movable bed the heterogeneous mixture flow was observed (Doron and Barnea, 1993, 1996).

\section{LOCAL CONCENTRATION}

Distribution of the local concentration in the pipe crosssection is important for understanding the mechanism of the heterogeneous mixture flow; it has a great effect on both the mixture's flow behaviour and pressure drop.

Various methods have been used for measurement of the local concentration, e.g. isokinetic sampling, different visualization techniques, electrical resistance and capacity or radiometric methods (Kaushal, Tomita, 2013; Kaushal et al., 2005; Krupicka and Matousek, 2012, 2014; Matousek, 2009; Matousek et al., 2015; Petryka et al., 2005; Przewlocki et al., 1979; Sobota et al., 2009; Zych et al., 2014). The volumetric concentration distribution in the inclined pipe sections was measured using a $\gamma$-ray densitometer and the effects of mixture velocity and concentration on the chord-averaged concentration profiles and concentration maps were analysed.

\section{Concentration profiles}

The effect of mean concentration, mixture velocity and angle of pipe inclination on local concentration distribution in chordaveraged vertical profiles was studied. The measured concentration profiles for different transport concentration $c_{d}$ confirmed the stratified flow pattern of the coarse particle-water mixture in inclined pipe sections, see Figs. $5-8$.

The chord averaged concentration profiles can be divided into three parts similarly as in horizontal pipe sections (Vlasak et al., 2014b, 2015, 2016). The local volumetric concentration $c_{v}$ approaches practically zero in the upper portion of the pipe. The zero-concentration region increases for the descending flow direction, with decreasing mixture velocity and mean transport concentration. A nearly linear concentration distribution was determined in the central portion of the pipe crosssection. Near the pipe invert, solids concentration reached maximum, and for the higher mixture velocity a thin layer with nearly constant local concentration was formed. However, the bed concentration in inclined pipe sections never reached values close to the loose-packed value for studied conditions.

Similarly as it was confirmed for pressure drop, the effect of pipe inclination for low values of inclination angle $\alpha$ (up to about $30^{\circ}$ ) is not significant (Vlasak et al., 2013b, 2014c, 2015), especially in the upper and central portions of the pipe, see Fig. 5. Local concentration $c_{v}$ slightly decreased with increasing pipe inclination at the pipe bottom. For higher values of inclination angle $\alpha$, a decrease in concentration close to the pipe invert was observed. In the direction to the pipe top the local concentration in the central portion of the pipe gradually decreased. For the vertical pipe a nearly constant concentration distribution was observed. The effect of inclination angle $\alpha$ was similar for both higher mixture velocities, for low mixture velocity $\left(V_{s}=2.05 \mathrm{~m} \mathrm{~s}^{-1}\right)$ a no bed layer was observed near the pipe invert. 

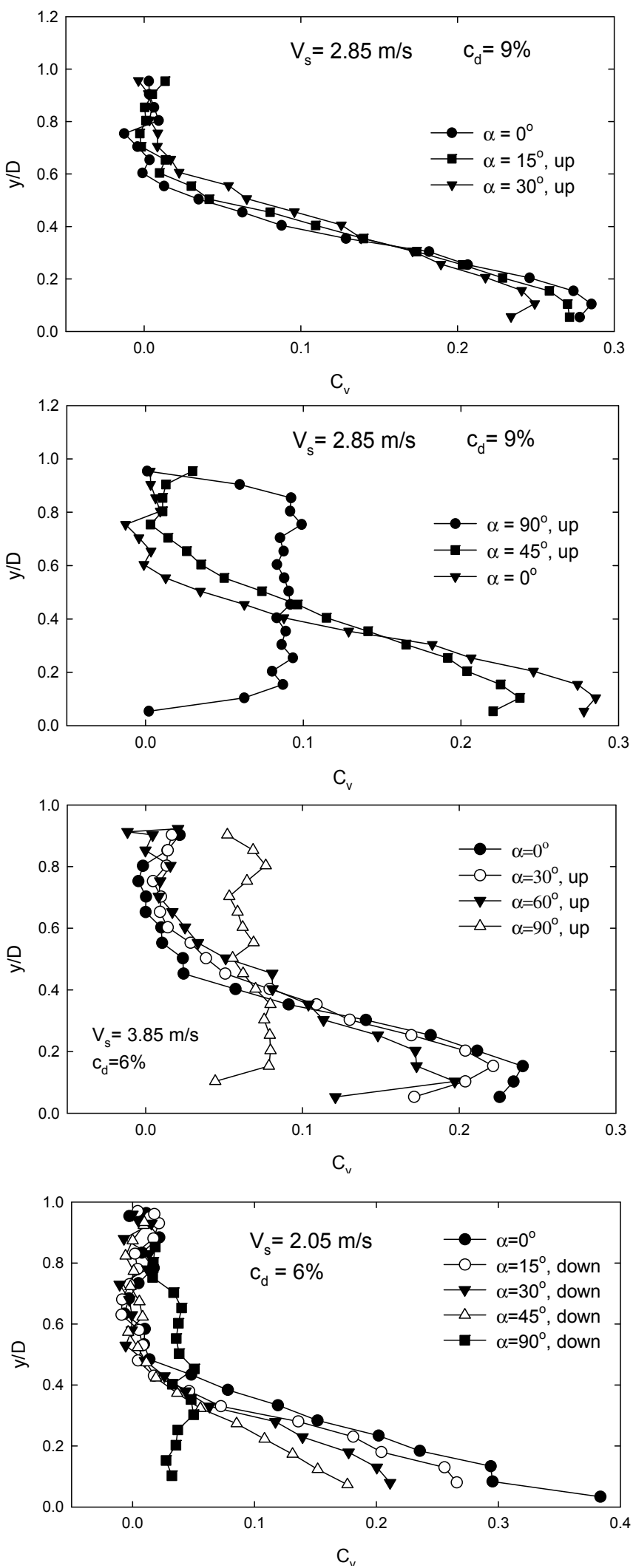

Fig. 5. Chord-averaged profiles of local concentration, $c_{v}$, effect of the inclination angle $\alpha$ (constant transport concentration $c_{d}$ and mean mixture velocity $V_{s}$ ).

The same was observed from Fig. 6, which illustrate the effect of mean mixture velocity $V_{s}$ for pipe section inclination angle $\alpha=15^{\circ}$ and $30^{\circ}$, and mean transport concentration $c_{d}=6 \%$.
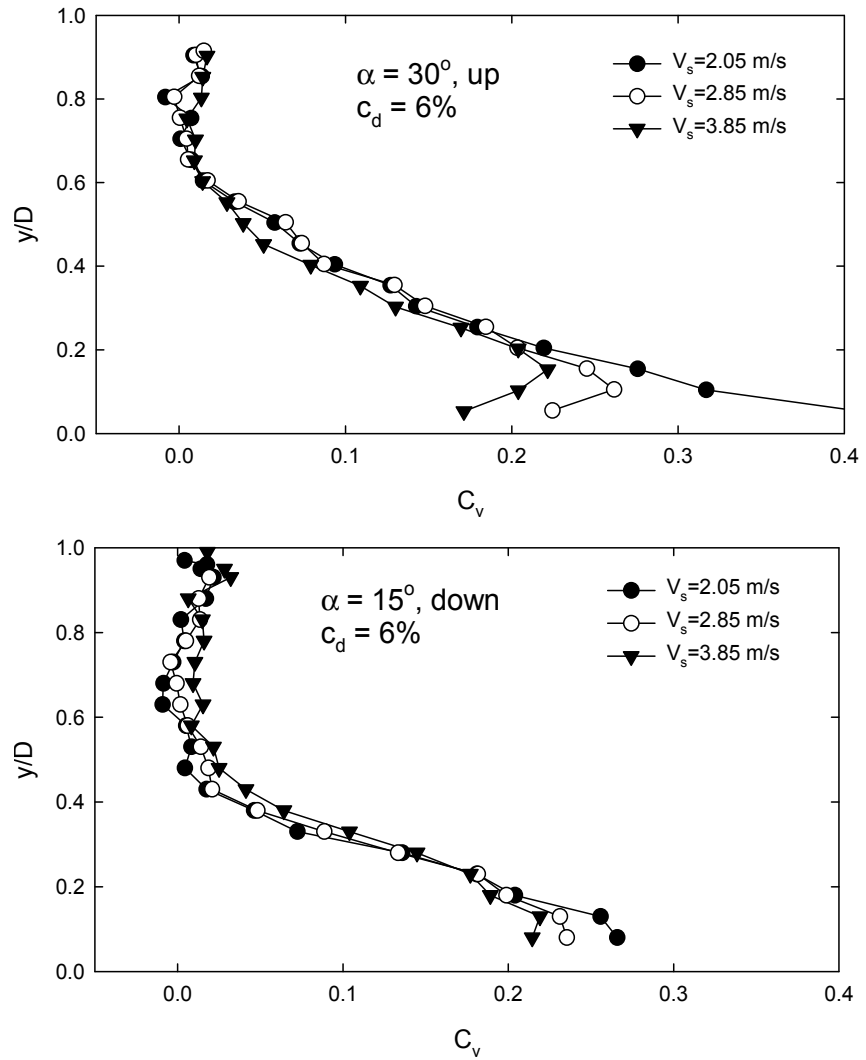

Fig. 6. Chord-averaged profiles of local concentration, $c_{v}$, effect of the mean mixture velocity $V_{s}$ (constant transport concentration $c_{d}$ and inclination angle $\alpha$ ).

Bed layer with thickness of about $20 \%$ of the pipe diameter were formed for moderate and higher mixture velocities. Local concentration in the bed layer decreased with increasing velocity; this effect increased with increasing inclination angle $\alpha$. Probably due to increasing saltation intensity more particles reach higher portion of the pipe cross-section.

Fig. 7 illustrates the effect of the mean transport concentration $c_{d}$ for inclination angle $\alpha=30^{\circ}$ and the mean mixture velocity $V_{s}=2.85 \mathrm{~m} \mathrm{~s}^{-1}$, both for ascending and descending flow directions. With increasing mean transport concentration the local concentration in the bed layer, as well as in central proportion of the pipe increased, and in ascending flow direction the bed layer was distinct even for low concentration value. No maximum of local concentration was observed for descending flow direction, concentration profiles were nearly linear in the lower portion of the pipe, and the zero concentration part of the chord-averaged concentration profile was significantly more extended than that for the ascending flow direction due to the braking effect of gravity force on ascending flow and accelerating effect of gravity force on descending flow. The positive effect of gravity decreases and the negative effect of gravity increases the particle velocity.

The effect of up and down flow is clearly illustrated in Figure 8 , for low and high mixture velocities $\left(V_{s}=2.05\right.$ and $3.85 \mathrm{~m} \mathrm{~s}^{-1}$ ), and inclination angle $\alpha$ in range from $15^{\circ}$ to $90^{\circ}$. The local concentration in ascending pipe section is always higher than that in descending pipe section. It is valid also for vertical up-ward and down-ward flow, where difference between the concentration values corresponds to particle slip velocity. 

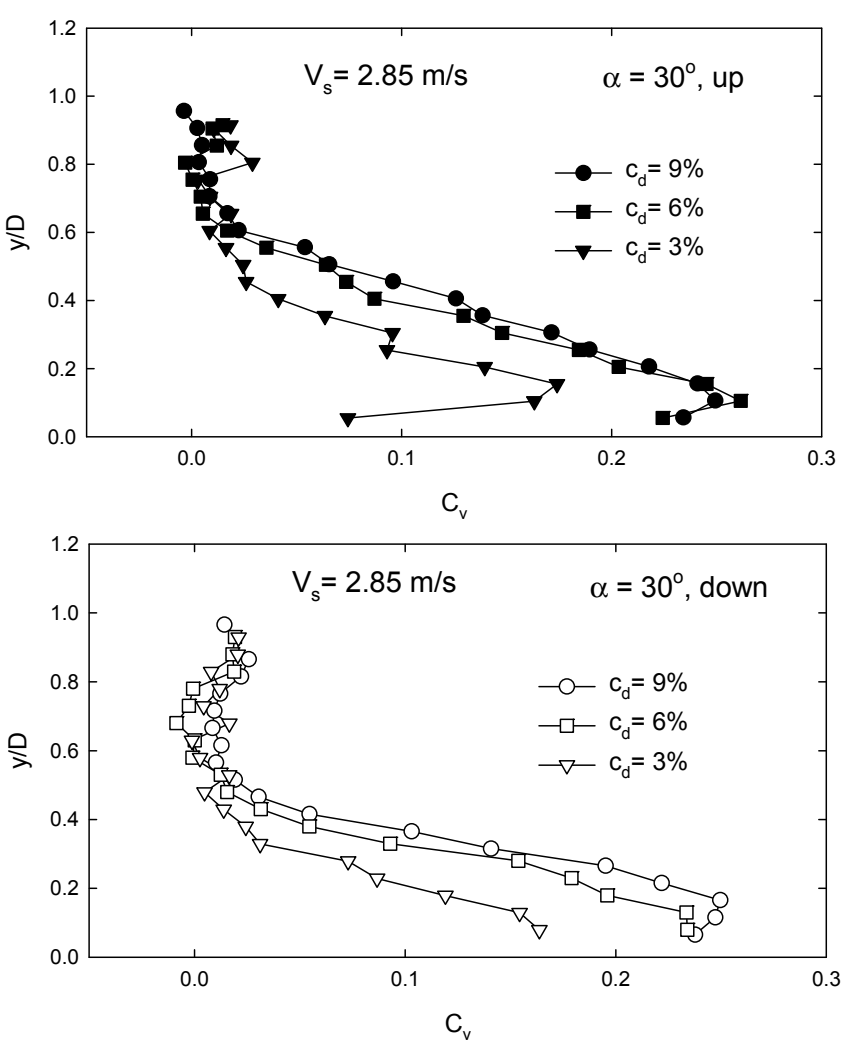

Fig. 7. Chord-averaged profiles of local concentration, $c_{v}$, effect of the transport concentration $c_{d}$ (constant mean mixture velocity $V_{s}$ and inclination angle $\alpha$ ).
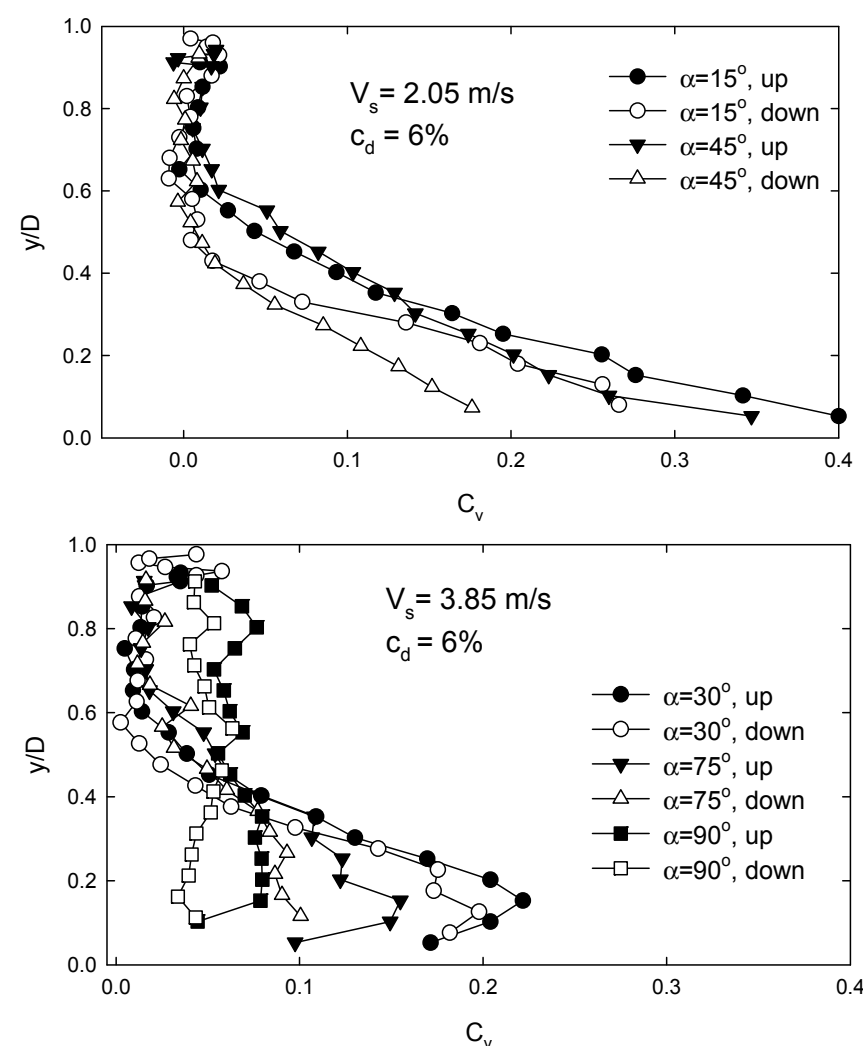

Fig. 8. Chord-averaged profiles of local concentration, $c_{v}$, effect of the ascending and descending flow (constant transport concentration $c_{d}$ and mean mixture velocity $V_{s}$ ).

\section{Concentration maps in inclined pipe sections}

The concentration maps measured in inclined pipe sections (see Fig. 9) confirmed that coarse particles tended to occupy the bottom part of the pipe. However, with increasing mixture velocity and concentration, even the coarse particles lifted off the pipe bottom and moved up to the central area of the pipe, similarly as it was found in the horizontal pipe section (Vlasak et al., 2014c). Some differences were found for ascending and descending flow direction due to the effect of gravity force on particle movement. In descending pipe sections the observed local concentration near lateral walls of the pipe was slightly less than that in the ascending pipe sections, where especially for higher mean concentration significantly higher local concentration values were reached close to the pipe invert, probably due to the higher slip velocity and breaking effect of the gravity force acting on the particles.

\section{Concentration maps in vertical pipe sections}

Local concentration maps in the ascending and descending vertical pipe sections illustrated effect of particle fall velocity on mixture concentration, see Fig. 10. The in situ concentration reached higher values in the ascending section than in the descending section, since the fall velocity decreased the absolute particle velocity, and thus increased the particle slip velocity and in-situ concentration in the ascending pipe section. For the descending pipe sections the opposite is valid and the in situ concentration is less than transport concentration.

Similarly to the inclined pipe sections the flow pattern and concentration distribution was observed different in the ascending and descending pipe section. In the ascending pipe section the maximum concentration was located in an annulus from about $h=0.15 \mathrm{D}$ to $h=0.30 \mathrm{D}$, with increasing flow velocity the difference of local concentration in the central portion and region with a maximum concentration decreased. For the descending pipe section the local concentration reached its maximum in the central portion of the pipe and in the direction to the pipe wall the local concentration smoothly decreased, and for higher flow velocities and lower mean concentrations became surprisingly low close to the pipe wall.

\section{CONCLUSIONS}

The effect of slurry velocity and mean concentration on a narrow particle size distribution basalt pebbles (mean diameter $d_{50}=11.5 \mathrm{~mm}$ ) - water mixtures' flow behaviour in the turbulent regime was studied in inclined and vertical smooth pipe sections of inner diameter $D=100 \mathrm{~mm}$.

Concentration distribution in ascending and descending vertical pipe section confirmed effect of fall velocity on particlecarrier liquid slip velocity and higher in situ concentration in ascending pipe section.

The visualization and local concentration measurements revealed the stratified flow pattern of the coarse particle-water mixture in inclined pipe sections, the particles moved principally in an area close to the pipe invert, where dune formations and for velocities higher than deposition limit a sliding bed layer were formed. For moderate and higher mixture velocities, particle saltation became the dominant mode of sediment transport.

The concentration maps confirmed that the in situ concentration reached higher values in the ascending section than in the descending section. In the vertical ascending pipe section the maximum concentration was located in an annulus from about 
transport concentration $c_{d}=3 \%$
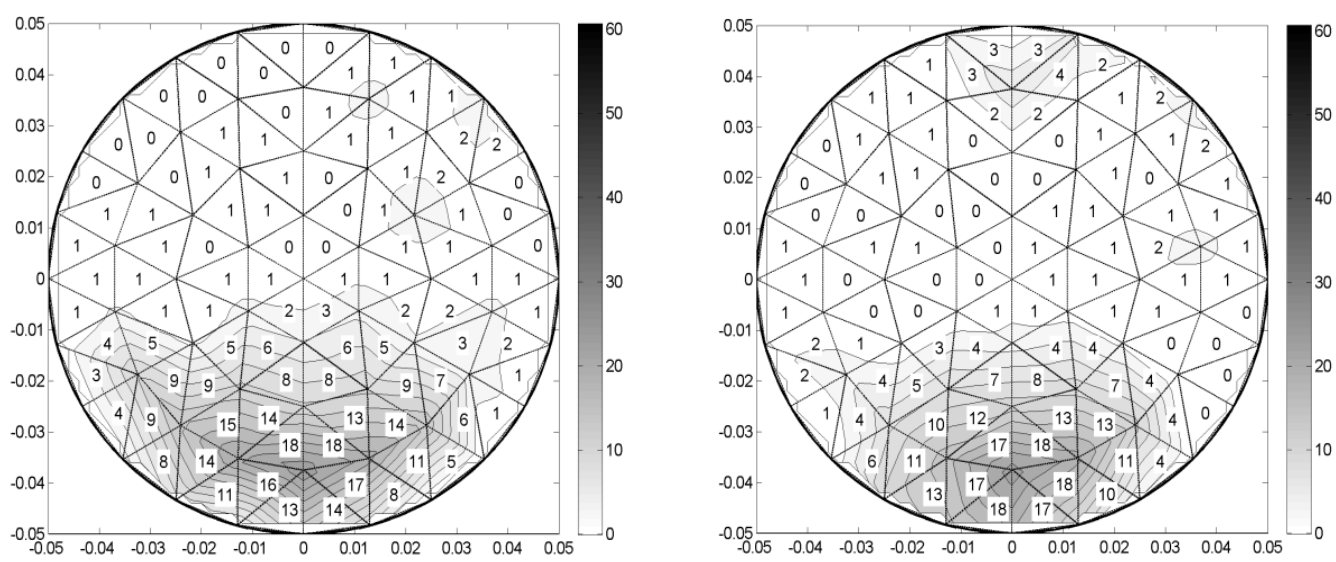

transport concentration $c_{d}=6 \%$
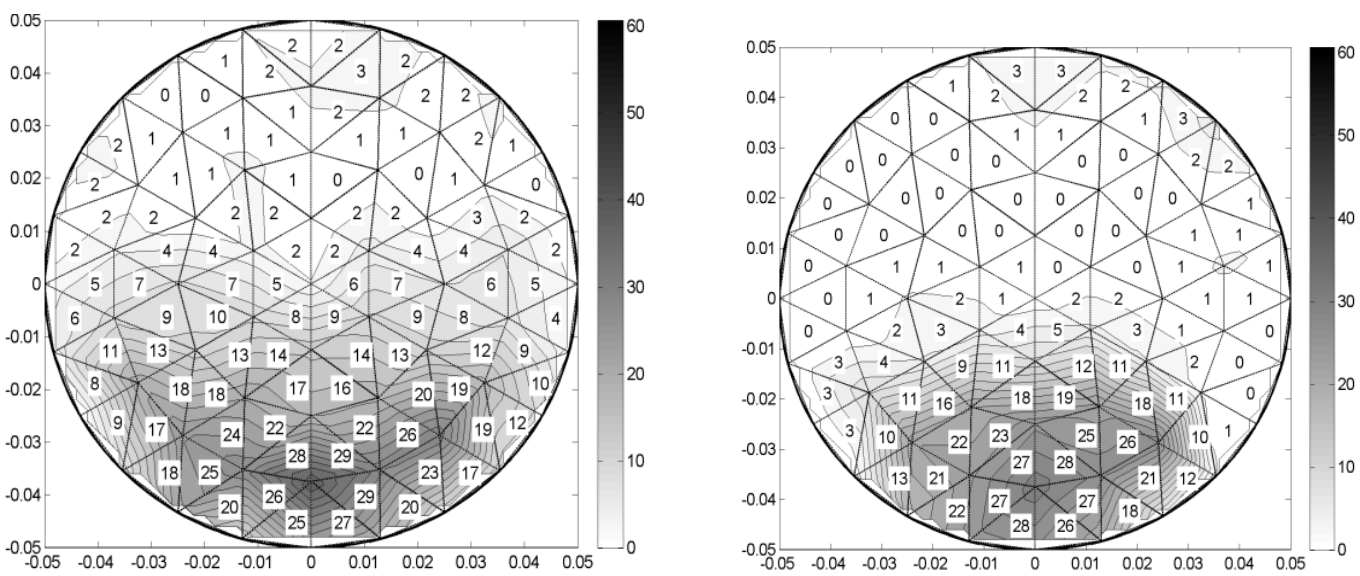

transport concentration $c_{d}=9 \%$

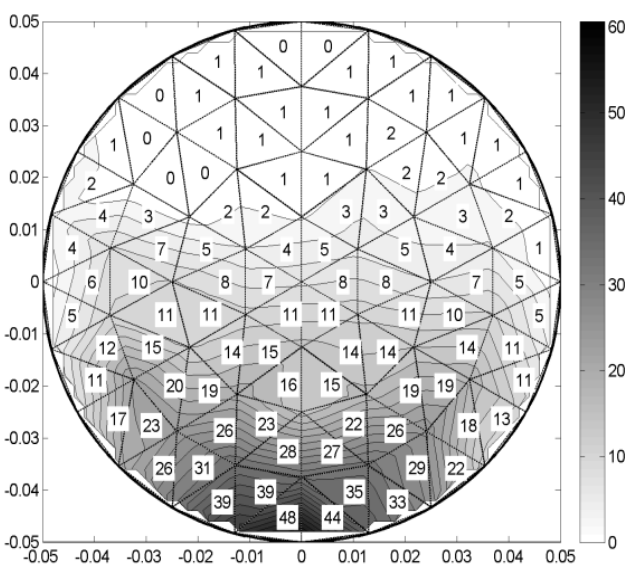

ascending flow

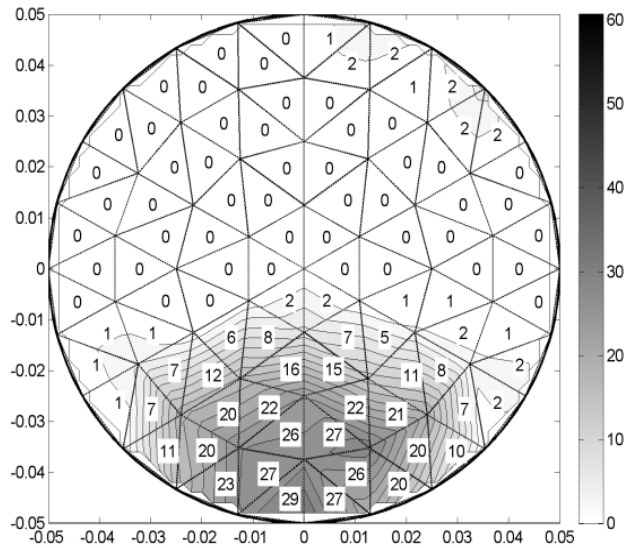

descending flow

Fig. 9. Maps of local concentration distribution $c_{v}$ in inclined pipe (inclination angle $\alpha=30^{\circ}$, mean mixture velocity $\mathrm{V}_{\mathrm{s}}=2.86 \mathrm{~m} \mathrm{~s}^{-1}$ ).

$h=0.15 \mathrm{D}$ to $h=0.30 \mathrm{D}$, contrary to the descending pipe section, where the local concentration reached its maximum in the central portion of the pipe.

In the inclined pipe sections, similarly to horizontal one, the chord averaged concentration profiles can be divided in three parts: a region near the pipe invert, where concentration reached a maximum, the central portion of the pipe with a nearly linear concentration distribution, and the zeroconcentration region in the upper portion of the pipe.
For lower values of inclination angle $\alpha$ (up to about $30^{\circ}$ ), the effect of pipe inclination on local concentration distribution is not significant, especially in the upper and central portion of the pipe. The zero concentration region increases for descending flow direction with decreasing mixture velocity and mean transport concentration. With increasing mean mixture velocity the local concentration in the bed layer slightly decreased; this effect increased with increasing inclination angle. 
transport concentration $c_{d}=3 \%$, mixture velocity $V_{s}=2.85 \mathrm{~m} \mathrm{~s}^{-1}$


transport concentration $c_{d}=6 \%$, mixture velocity $V_{s}=3.85 \mathrm{~m} \mathrm{~s}^{-1}$
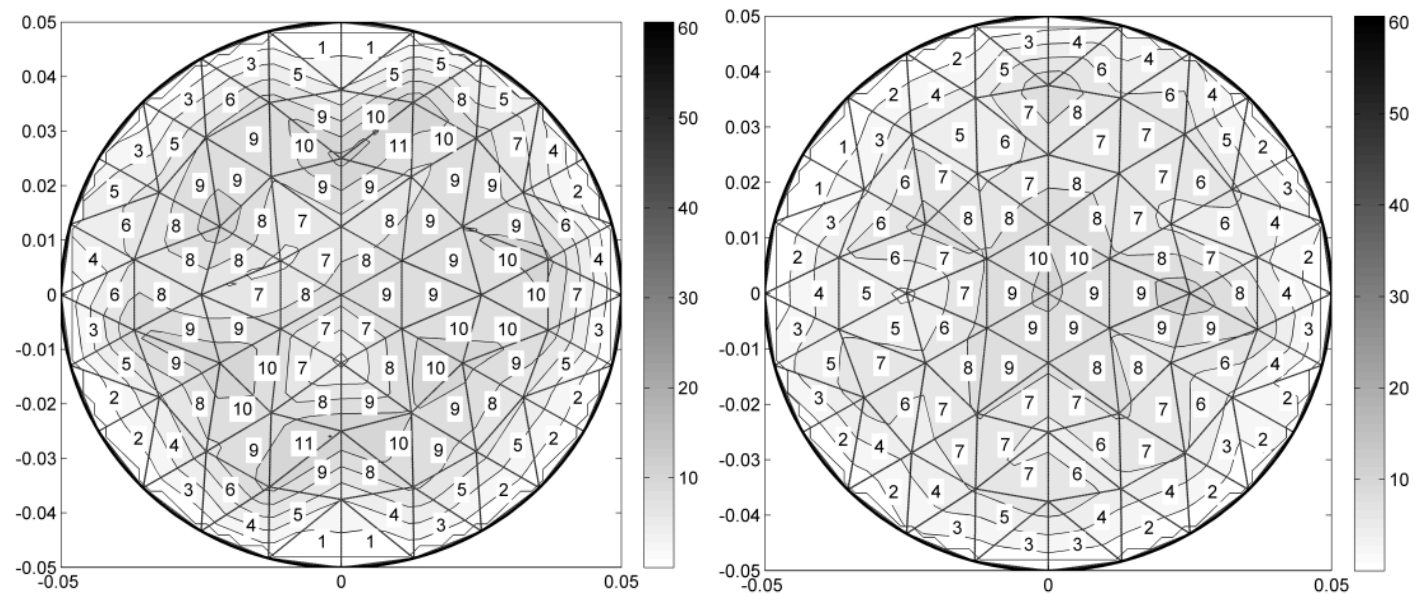

transport concentration $c_{d}=9 \%$, mixture velocity $V_{s}=2.85 \mathrm{~m} \mathrm{~s}^{-1}$

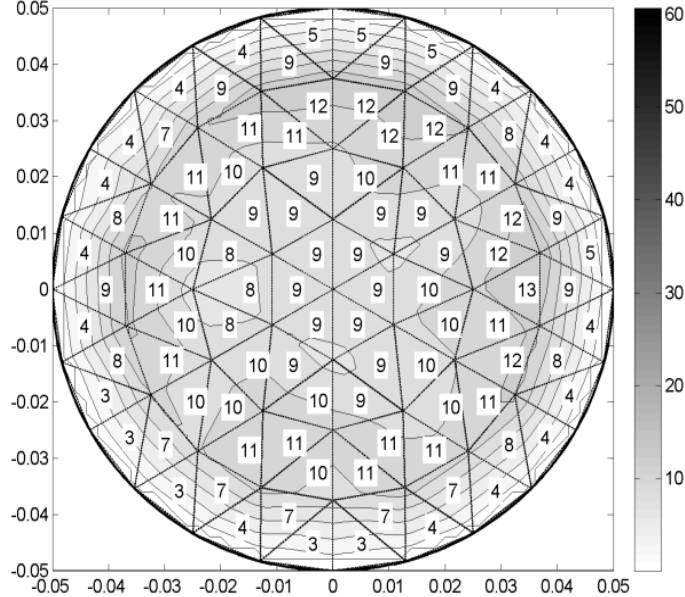

ascending flow direction

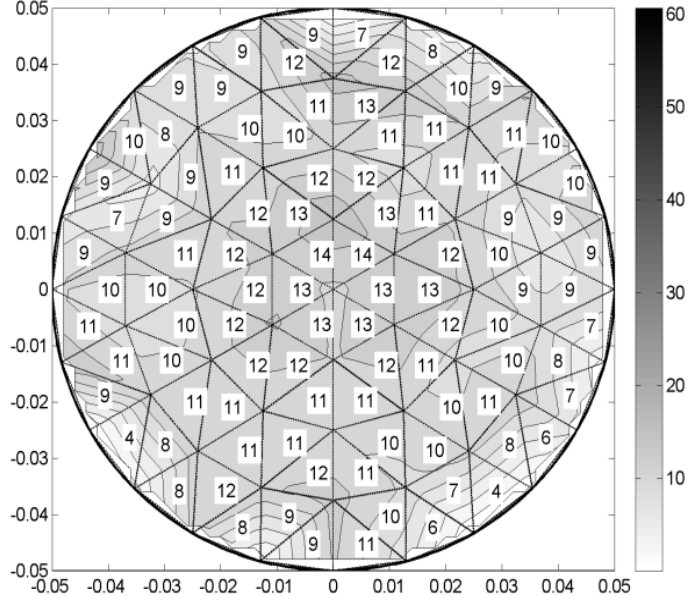

descending flow direction

Fig. 10. Maps of local volumetric concentration distribution $c_{v}$ in vertical pipe.

The zero-concentration region for descending flow is bigger than that for the ascending flow direction. In descending pipe sections the local concentration near lateral walls of the pipe was slightly less than that in the ascending pipe sections.
Acknowledgements. Supports under the project P105/10/1574 of the Grant Agency of the Czech Republic, and RVO: 67985874 of the Czech Academy of Sciences are gratefully acknowledged. 


\section{REFERENCES}

Campbell, C.S., Francisco, A.S., Liu, Z., 2004. Preliminary observations of a particle lift force in horizontal slurry flow. Int. J. Multiphase Flow, 30, 199-216.

Doron, P., Barnea, D., 1993. A three layer model for solidliquid flow in horizontal pipes. Int. J. Multiphase Flow, 19, 6, 1029-1043.

Doron, P., Barnea, D., 1996. Flow pattern maps for solid-liquid flow in pipes. Int. J. Multiphase Flow, 22, 2, 273-283.

Durand, R., 1953. Concentration measuring instrument for hydraulic transportation installation. La Houille Blanche, 8, 2, 296-297.

Gilies, R.G., Shook, C.A., Wilson, K.C, 1991. An improved two layer model for horizontal slurry flow. Can. J. Chemical Engineering, 69, 173-178.

Kao, D.T.Y., Hwang, L.Y., 1979. Critical slope for slurry pipeline transporting coal and other solid particles. In: Burns, A.P. (Ed.): Proc. 6th Int. Conf. on the Hydraulic Transport of Solids in Pipes - HYDROTRANSPORT, Canterbury (U.K.), BHRA Fluid Engineering Centre, Cranfield (U.K.), Vol. 1, Pap. A5, pp. 57-74.

Kaushal, D.R., Tomita, Y., 2013. Prediction of concentration distribution in pipeline flow of highly concentrated slurry. Particulate Science and Technology, 31, 28-34.

Kaushal, D.R., Sato, K., Toyota, T., Funatsu, K., Tomita, Y., 2005. Effect of particle size distribution on pressure drop and concentration profile in pipeline flow of highly concentrated slurry. Int. J. Multiphase Flow, 31, 809-823.

Krupicka, J., Matousek, V., 2012. Gamma-ray-based method for density sensing in pipes - evaluation of measurement and data processing. In: Proc. 2nd IAHR Europe Congr., Munich (Germany), 27-30 June 2012.

Krupicka, J., Matousek, V., 2014. Gamma-ray-based measurement of concentration distribution in pipe flow of settling slurry: vertical profiles and tomographic maps. J. Hydrol. Hydromech., 62, 2, 126-132.

Lukerchenko, N., Chara, Z., Vlasak, P., 2006. 2D numerical model of particle-bed collision in fluid-particle flows over bed. J. Hydraulic Research, 44, 1, 70-78.

Lukerchenko, N., Piatsevich, S., Chara, Z., Vlasak, P., 2009. 3D numerical model of a spherical particle saltation in channel with rough fixed bed. J. Hydrol. Hydromech., 57, 2, $100-112$.

Maciejewski, W., Oxenford, J., Shook, C. A., 1993. Transport of coarse rock with sand and clay slurries. In: Proc. 12th Int. Conf. on Slurry Handling and Pipeline Transport - HYDROTRANSPORT 12. BHR Group, Brugge (Belgium), pp. 705-724.

Matousek, V., 2009. Concentration profiles and solids transport above stationary deposit in enclosed conduit. J. Hydraulic Engineering ASCE, 135, 12, 1101-1106.

Matousek, V., Vlasak, P., Chara, Z., Konfrst, J., 2015. Experimental study of hydraulic transport of coarse-basalt. Maritime Engineering, 168, 93-100.

Newitt, D.M., Richardson, J.F., Abbott, M., Turtle, R.B., 1955. Hydraulic conveying of solids in horizontal pipes. Transactions Institute Chemical Engineers, 33, 2, 93-113.

Petryka, L., Zych, M., Murzyn, R., 2005. The non-stationary two-phase flow evaluation by radioisotopes. Nukleonika, 50, 43-46.

Pullum, L., Graham, L.J. W., Slatter, P., 2004. A nonNewtonian two-layer model and its application to high density hydrotransport. In: N. Heywood (Ed.): Proc. 16th Int.
Conf. on Hydrotransport, 26-28 April 2004, Vol. II. BHR Group, Santiago de Chile, pp. 579-594.

Przewlocki, K., Michalik, A., Wolski, K., Korbel, K., 1979. A radiometric device for the determination of solids concentration distribution in a pipeline. In: Burns, A.P. (Ed.): Proc. 6th Int. Conf. on the Hydraulic Transport of Solids in Pipes HYDROTRANSPORT 6, Canterbury (UK), BHRA Fluid Engineering Centre, Cranfield (U.K.), Pap. B3, pp. 219-227.

Shook, C.A., Roco, M.C., 1991. Slurry Flow: Principles and Practice. 1st Ed. Butterworth/Heinemann, Boston 1991.

Shook, C.A., Geller, L., Gillies, R.G., Husband, W.H.W., Small, M., 1986. Experiments with coarse particles in a 250 mm pipeline. In: Burns, A.P. (Ed.): Proc. 10th Int. Conf. on the Hydraulic Transport of Solids in Pipes - HYDROTRANSPORT 10, Innsbruck (Austria). BHRA Fluid Engineering Centre, Cranfield (U.K.), pp. 219-227.

Sobota, J., Vlasak, P., Strozik, G., Plewa, F., 2009. Vertical distribution of concentration in horizontal pipeline - density and particle size influence. In: Proc. 8th ISOPE Ocean Mining (\& Gas Hydrates) Symposium, Chennai (India), 20-24 September 2009, pp. 220-224.

Sumner, R.J., McKibben, M., Shook, C.A., 1990. Concentration and velocity distribution in turbulent vertical slurry flow. J. Solid Liquid Flow, 2, 2, 33-42.

Thomas, A.D., Wilson, K.C., 1987. New analysis of nonNewtonian turbulent flow - Yield-power-law fluids. Can. J. Chemical Engineering, 65, 335-338.

Vlasak, P., Chara, Z., 2007. Effect of particle size and concentration on flow behavior of complex slurries. In: Proc. 7th ISOPE Ocean Mining Symp., Lisbon, pp. 188-196.

Vlasak, P., Chara, Z., 2011. Effect of particle size distribution and concentration on flow behaveior of dense slurries. Particulate Science and Technology, 29, 1, 53-65.

Vlasak, P., Chara, Z., Kysela B., Sobota, J., 2011. Flow behavior of coarse-grained slurries in pipes. In: Proc. 9th (2011) ISOPE (Deep) Ocean Mining ( \& Gas Hydrates) Symposium, 19-25 June 2011, Maui (Hawaii, USA), pp. 158-164.

Vlasak, P., Kysela, B., Chara, Z., 2012. Flow Structure of coarse-grained slurry in horizontal pipe. J. Hydrol. Hydromech., 60, 2, 115-124.

Vlasak, P., Chara, Z., Konfrst, J., Kysela, B., 2013a. Experimental investigation of coarse-grained particles in pipes, In: Proc. 16th Int. Conf. on Transport \& Sedimentation of Solid Particles, Rostock (Germany), 18-20 September 2013, pp. 265-273.

Vlasak, P., Chara, Z., Konfrst, J., Sobota, J., Kysela, B., 2013 b. Conveying of coarse-grained particles in pipes. In: Proc. 10th (2013) ISOPE Ocean Mining \& Gas Hydrates Symposium, Szcezecin (Poland), 22-26 September 2013, pp. 215220.

Vlasak, P., Kysela, B., Chara, Z., 2014a. Fully stratified particle-laden flow in horizontal circular pipe, Particulate Science and Technology, 32, 2, 179-185.

Vlasak, P., Chara, Z., Konfrst, J., Krupicka, J., 2014 b. Experimental investigation of coarse particle conveying in pipes. EPJ Web of Conferences, Experimental Fluid Mechanics 2014, 18-21 November, Cesky Krumlov (Czech Rep.), pp. 712-719.

Vlasak, P., Chara, Z., Krupicka, J., Konfrst, J., 2014c. Experimental investigation of coarse particles-water mixture flow in horizontal and inclined pipes. J. Hydrol. Hydromech., 62, 3, 241-247.

Vlasak, P., Chara, Z., Konfrst, J., 2015. Conveying of coarse particles in horizontal and inclined pipes. In: 17th Int.Conf. 
on Transport \& Sedimentation of Solid Particles, Delft (the Netherlands), September 22-25, 2015, pp. 355-362.

Vlasak, P., Chara, Z., Konfrst, J., Krupicka, J., 2016. Distribution of concentration of coarse particle-water mixture in horizontal smooth pipe. Canadian Journal of Chemical Engineering, 94, 1040-1047.

Wilson, K.C., 1976. A unified physically based analysis of solid-liquid pipeline flow, In: Proc. 4th Int. Conf. on the Hydraulic Transport of Solids in Pipes - HYDROTRANSPORT 4, B.H.R.A., Banff (Canada), 18-21 May 1976, Pap. A1.

Wilson, K.C., Addie, G.R., 1997. Coarse-particle pipeline transport: effect of particle degradation on friction. Powder Technology, 94, 235-238.

Wilson, K.C., Brown, N.P., Streat, M., 1979. Hydraulic hoisting at high concentration: A new study of friction mechanisms. In: Proc. 6th Int. Conf. on Hydraulic Transport of Solids in Pipes (HYDROTRANSPORT 6). Cranfield, Bedford (UK), BHRA Fluid Engineering, pp. 269-282.

Wilson, K.C., Addie, G.R., Sellgren, A., Clift, R., 2006. Slurry Transport Using Centrifugal Pumps. 3rd Ed. Springer, New York, Philadelphia.

Wilson, K.C., Sanders, R.S., Gillies, R.G., Shook, C.A., 2010. Verification of the near-wall model for slurry flow. Powder Technology, 197, 247-253.

Zych, M., Petryka, L., Kępinski, J., Hanus, R., Bujak, T., Puskarczyk, E. 2014. Radioisotope investigations of compound two-phase flows in an open channel flow. Measurement and Instrumentation, 35, 11-15.

Received 9 August 2016 Accepted 26 September 2016 